Annemarie Docherty Timothy S. Walsh

\section{Should blood transfusion be individualised? We are not sure}

Received: 31 July 2015

Accepted: 12 August 2015

Published online: 10 September 2015

(C) Springer-Verlag Berlin Heidelberg and ESICM 2015

For contrasting viewpoints please go to

doi:10.1007/s00134-015-3948-1 and

doi:10.1007/s00134-015-3950-7.

A. Docherty · T. S. Walsh (®)

Anaesthetics, Critical Care and Pain Medicine, Edinburgh

University, Room S8208, 2nd Floor, Edinburgh, UK

e-mail: twalsh@staffmail.ed.ac.uk

Tel.: 01312426395

\section{A. Docherty}

e-mail: Annemarie.Docherty@ed.ac.uk

Tel.: 01312426395

\section{A. Docherty · T. S. Walsh}

Royal Infirmary of Edinburgh, 51 Little France Crescent, Edinburgh, Scotland EH16 4SA, UK

We think the evidence supports a restrictive blood transfusion threshold using a haemoglobin concentration $(\mathrm{Hb})$ trigger of $70 \mathrm{~g} / \mathrm{L}$ in younger, less sick patients in ICUs, especially those without co-existing cardiorespiratory co-morbidity $[1,2]$. More liberal transfusion could increase important complications without clinical benefit [3]. In addition, red blood cells are expensive and no trials have demonstrated their cost-effectiveness. Unfortunately, many of our patients are sick, older, and have cardiorespiratory co-morbidity. It is these patients in whom we think individualised transfusion threshold decisions may be needed.

\section{Physiological arguments against a blanket restrictive Hb trigger}

There is biological plausibility for maintaining higher $\mathrm{Hb}$ levels, and by inference, higher oxygen delivery in higher risk patients, such as those with cardiovascular disease and acute severe sepsis. Specifically, the frequent presence of both tachycardia and hypotension in the critically ill, the requirement for catecholamines that increase myocardial work, and the high coronary oxygen extraction ratio support the argument for higher $\mathrm{Hb}$ values in the presence of coronary disease. Coronary oxygen supplydemand imbalance may result in "type II" myocardial infarction or injury. Troponin release is prevalent in the critically ill and is associated with higher mortality [4, 5].

In sepsis, oxygen supply-demand imbalances may occur regionally, with arteriovenous shunting, resulting in a hypoxaemic microcirculation despite global haemodynamics appearing relatively normal [6, 7]. Red blood cell transfusion may improve oxygen content and availability by recruiting the microcirculation [8]. Many septic patients have cardiovascular co-morbidity, raising the possibility of a "double hit" from severe anaemia in this population. Is a transfusion trigger of $70 \mathrm{~g} / \mathrm{L}$ really safe for all of these cases?

\section{What does the high quality evidence tell us?}

The FOCUS trial [9] enrolled elderly patients with cardiovascular disease undergoing hip surgery and found no difference in a composite outcome of mortality or inability to walk independently at 60 days (OR liberalstrategy $1.01,95 \%$ CI $0.84-1.22)$. This high quality trial 
is correctly quoted as evidence that restrictive transfusion practice is safe, but how restrictive? The mean (SD) restrictive $\mathrm{Hb}$ trigger was $79(6) \mathrm{g} / \mathrm{L}$ and most patients were only exposed to $\mathrm{Hb}$ values below $90 \mathrm{~g} / \mathrm{L}$ for less than 3 days. In fact the restrictive arm used individualised triggers based on patients' symptoms and signs. FOCUS is therefore not strong evidence that $70 \mathrm{~g} / \mathrm{L}$ is "the new norm" for these patients.

The TRICC and TRISS trials are the highest quality evidence in the critically ill, and both used a restrictive $\mathrm{Hb}$ trigger of $70 \mathrm{~g} / \mathrm{L}[1,2]$. Both reported underpowered cardiovascular and/or ischaemic heart disease subgroup analyses; these showed (non-significant) point estimates that favoured liberal practice (TRICC ARR $4.0 \%, 95 \%$ CI -6.9 to 14.9; TRISS RR 1.08, $95 \%$ CI 0.75-1.40).

The median time to recruitment for TRISS was $21 \mathrm{~h}$ after ICU admission, and $14 \mathrm{~h}$ for TRICC, and in a smaller trial of older patients the delay was $96 \mathrm{~h}$ [10]. This excluded the early period of critical illness when arguably the oxygen supply-demand balance may be most deranged. The recent early goal-directed trials in sepsis (ProCESS, ARISE, and PROMISE), which included the use of red cell transfusions when the $\mathrm{Hb}$ was below $100 \mathrm{~g} / \mathrm{L}$ and $\mathrm{ScVO}_{2}$ below $70 \%$, found no outcome benefit overall [11], but relatively few patients triggered the blood transfusion part of the algorithm. It also seems unlikely that many patients had $\mathrm{Hb}$ below $70 \mathrm{~g} / \mathrm{L}$ during the intervention period. These trials were underpowered for patients with low $\mathrm{ScVO}_{2}$ and low $\mathrm{Hb}$ and, importantly, for patient subgroups with comorbidity such as cardiac disease. The possibility of differential, potentially opposite, effects from fixed interventions in heterogeneous critically ill populations has been illustrated in relation to transfusion [12] (Fig. 1). We are uncertain, therefore, that we have strong evidence that a fixed $70 \mathrm{~g} / \mathrm{L} \mathrm{Hb}$ trigger is safest for all patients.

\section{Are we ready for precision medicine in relation to transfusion?}

Mortality is not necessarily the best endpoint for blood transfusion trials in critically ill patients. Clinically important differences may occur that do not translate into mortality differences or are undetectable without very large sample sizes. This is particularly relevant in critical care where populations are heterogeneous in terms of comorbidity and acute pathology and where multiple factors influence the risk of death. In addition to this, anaemia persists in many patients after critical illness [13] and may contribute to the post-ICU syndrome that we are only starting to understand. There is a strong association between transfusion and quality of life in chronic anaemia syndromes [14]; the same might be true in recovering critically ill patients.

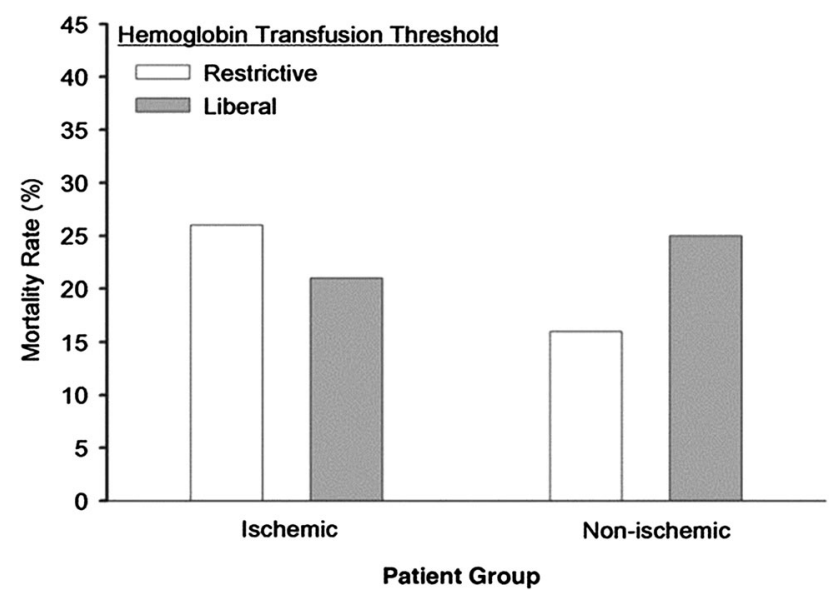

Fig. 1 The effect of transfusion strategy on mortality is dependent on the presence or absence prerandomization of ischaemic heart disease. In the TRICC transfusion trigger trial [1], the effects of transfusion thresholds on 30-day mortality were significantly different and opposite depending on the presence or absence prerandomization of ischaemic heart disease (Breslow-Day test; $p=0.03)$. In patients with ischaemic heart disease $(n=257)$, the use of a restrictive transfusion strategy increased mortality compared with the use of a liberal strategy. In patients without ischaemic heart disease $(n=581)$, the use of a restrictive transfusion strategy decreased mortality compared with the use of a liberal strategy. For this analysis, data from the original and subsequent publications were combined. Reproduced with permission from Deans et al. [12]

At present available methods for measuring cellular, tissue, or organ oxygenation status lack sensitivity and specificity. Perhaps the way forward is to explore novel measures of end organ perfusion to guide transfusion decisions. In relation to the heart, cardiac-specific enzymes such as troponin I or MyC (cardiac myosin binding protein $\mathrm{C}$ ) may quantify myocardial damage; similarly continuous ECG monitoring could detect the ischaemic burden placed on the heart. Myocardial infarction or injury seems an especially relevant endpoint for patients with cardiovascular disease. The diagnosis of myocardial infarction in the context of critical illness is often subjective, and understanding what levels of biochemically quantified injury are important could lead to future "precision medicine" trials exploring whether interventions such as blood transfusion can modify these outcomes.

\section{Conclusion}

As is often the case there is common ground in the debate. We agree the evidence supports a default $\mathrm{Hb}$ trigger of $70 \mathrm{~g} / \mathrm{L}$ for younger patients and those without cardiovascular disease (acute or chronic). For critically ill older patients, especially those with cardiac disease, we agree 
the general approach should be restrictive but are not sure that the evidence supports a "new norm" of $70 \mathrm{~g} / \mathrm{L}$ for all. We are not alone. An analysis of transfusion triggers in the international ABLE trial showed substantial variation, with ischaemic heart disease modifying behaviour [15]. Future studies need to develop strategies to inform precision medicine approaches that can be tested in trials in defined populations. This may enable evidence-based individualised transfusion therapy. Until then we will continue to require clinical judgement.

\section{Compliance with ethical standards}

Conflicts of interest The authors have no relevant conflicts of interest.

\section{References}

1. Hebert PC, Wells G, Blajchman M et al (1999) A multicenter, randomized, controlled clinical trial of transfusion requirements in critical care. $\mathrm{N}$ Engl $\mathrm{J}$ Med 340:409-417

2. Holst LB, Haase N, Wetterslev J et al (2014) Lower versus higher hemoglobin threshold for transfusion in septic shock. N Engl J Med 371:1381-1391. doi:10.1056/NEJMoa1406617

3. SHOT Steering Group (2013) Annual SHOT report 2013. SHOT, Manchester

4. Ostermann M, Lo J, Toolan M et al (2014) A prospective study of the impact of serial troponin measurements on the diagnosis of myocardial infarction and hospital and six-month mortality in patients admitted to ICU with non-cardiac diagnoses. Crit Care 18:R62. doi:10.1186/cc13818

5. Lim W, Qushmaq I, Deveraux P et al (2006) Elevated cardiac troponin measurements in critically Ill patients. J Am Med Assoc 166:2446-2454

6. Ellis C, Bateman R, Sharpe $M$ et al (2002) Effect of a maldistribution of microvascular blood flow on capillary $\mathrm{O}_{2}$ extraction in sepsis. Am J Physiol Heart Circ Physiol 282:H156-H164
7. Ince C, Sinaasappel M (1999)

Microcirculatory oxygenation and shunting in sepsis and shock. Crit Care Med 27:1369-1377

8. Yuruk K, Almac E, Bezemer R et al (2011) Blood transfusions recruit the microcirculation during cardiac surgery. Transfusion 51:961-967

9. Carson J, Terrin M, Noveck $\mathrm{H}$ et al (2011) Liberal or restrictive transfusion in high-risk patients after hip surgery. N Engl J Med 365:2453-2462

10. Walsh TS, Boyd JA, Watson D et al (2013) Restrictive versus liberal transfusion strategies for older mechanically ventilated critically ill patients: a randomized pilot trial. Crit Care Med 41:2354-2363. doi: 10.1097/CCM.0b013e318291cce4

11. Angus DC, Barnato AE, Bell D et al (2015) A systematic review and metaanalysis of early goal-directed therapy for septic shock: the ARISE, ProCESS and ProMISe Investigators. Intensive Care Med. doi: 10.1007/s00134-015-3822-1

12. Deans K, Minneci P, Suffredini A et al (2007) Randomization in clinical trials of titrated therapies: unintended consequences of using fixed treatment protocols. Crit Care Med 35:1509-1516
13. Bateman A, McArdle F, Walsh $\mathrm{T}$ (2009) Time course of anemia during six months follow up following intensive care discharge and factors associated with impaired recovery of erythropoiesis. Crit Care Med 37:1906-1912

14. Jansen A, Essink-Bot M, Beckers E et al (2003) Quality of life measurement in patients with transfusion-dependent myelodysplastic syndromes. Br J Haematol 121:270-274

15. Wilton K, Fowler R, Walsh $\mathrm{T}$ et al (2014) Variation in red blood cell transfusion thresholds in critically ill patients. Crit Care 18:106 